Versão PDF da entrada

\title{
Regressões ao Infinito em Metafísica
}

URI:

da EDIÇÃO DE 2013 do

\section{COMPÊNDIO EM LINHA}

de Problemas de Filosofia Analítica

2012-2015 FCT Project PTDC/FIL-FIL/121209/2010



Editado por

João Branquinho e Ricardo Santos

ISBN: 978-989-8553-22-5

Compêndio em Linha de Problemas de Filosofia Analítica

Copyright (C) 2013 do editor

Centro de Filosofia da Universidade de Lisboa

Alameda da Universidade, Campo Grande, 1600-214 Lisboa

Regressões ao Infinito em Metafísica

Copyright (C) 2013 dos autores

João Branquinho e Guido Imaguire

Todos os direitos reservados 


\section{Regressões ao Infinito em Metafísica}

Este ensaio consiste num exame crítico da estrutura e do valor de um conjunto diverso de argumentos por regressão ao infinito que têm sido objecto de discussão recorrente na metafísica contemporânea.

O seminal livro de David Armstrong Nominalism and Realism (Armstrong 1978) contém uma das mais compreensivas discussões de argumentos regressivos em metafísica, os quais variam entre argumentos que foram de facto avançados ao longo da história da disciplina (como o Argumento do Terceiro Homem, de Platão) e argumentos construídos de novo por Armstrong para fins de exame crítico. Os argumentos regressivos discutidos por Armstrong têm como alvo uma grande variedade de teorias metafísicas acerca da semelhança e da predicação, entre as quais se contam o nominalismo de predicados, o nominalismo de conceitos, o nominalismo de classes, o nominalismo de semelhança e o realismo metafísico transcendente, de inspiração platónica.

Parte do presente ensaio visa contribuir para a discussão do tópico das regressões em metafísica através de uma reconstrução e reavaliação, executadas com alguma minúcia, de dois tipos de argumentos regressivos centrais e paradigmáticos, ambos discutidos por Armstrong: ${ }^{1}$

- a alegada regressão monádica ao infinito gerada pela explicação da predicação proposta pelo realismo metafísico (Armstrong 1978: 69-71);

- as alegadas regressões monádicas e diádicas ao infinito geradas pela explicação da predicação propostas pelo nominalis-

\footnotetext{
${ }^{1}$ Armstrong usa os termos "regressões de objecto" e "regressões relacionais" para aquilo que nós aqui preferimos designar como, respectivamente, "regressões monádicas" e "regressões diádicas". Os dois géneros de regressões são distinguidos em Armstrong 1978: 19-20. Por outro lado, a forma de realismo metafísico discutida por Armstrong é o realismo transcendente, de inspiração platónica. Todavia, discutimos neste ensaio argumentos regressivos que visam o realismo metafísico em geral, não apenas aquela versão particular. Concentramo-nos também na explicação da predicação, embora se possa generalizar razoavelmente daí para a explicação da semelhança.
}

Publicado pela primeira vez em 2013 
mo de classes (Armstrong 1978: 41-2).

A avaliação que Armstrong faz destes argumentos regressivos é, resumidamente, a seguinte. Relativamente ao nominalismo de classes, no caso monádico ou objectual não há sequer qualquer regressão ao infinito; todavia, no caso diádico ou relacional há uma regressão e trata-se de uma regressão viciosa. Relativamente ao realismo metafísico, Armstrong defende diagnósticos genericamente análogos aos obtidos em relação ao nominalismo de classes, embora as razões dadas e os detalhes sejam em cada caso significativamente diferentes.

Queremos corrigir os diagnósticos propostos por Armstrong para aqueles dois tipos de argumentos regressivos, e, por analogia, para diversos outros géneros de argumentos regressivos. A nossa correcção é de algum modo menor, no sentido de deixar relativamente intocada a direcção geral dos diagnósticos de Armstrong. Todavia, como vamos ver, não deixa por isso de ser uma correcção de alguma maneira substantiva, já que são feitas rectificações importantes naqueles diagnósticos.

Antecipando, os resultados que obtemos são da seguinte natureza:

- No caso monádico, quer em relação ao nominalismo de classes quer em relação ao realismo metafísico, nem sequer há regressões ao infinito, muito menos regressões viciosas, pois nem sequer são de facto geradas séries infinitas de explicações. Este resultado não parece ter sido suficientemente notado na literatura sobre o tópico. Armstrong também defende que não há regressões nestes casos, mas com base em razões completamente diferentes das nossas e, a nosso ver, inadequadas.

- No caso diádico ou relacional, quer em relação ao nominalismo de classes quer (por analogia) em relação ao realismo metafísico, é à primeira vista possível construir séries infinitas de explicações. Todavia, estas podem ser razoavelmente travadas seja qual for a teoria metafísica que se queira adoptar. Em todo o caso, também não há nestes casos regressões viciosas, o que entra em contraste com o veredicto defendido por Armstrong. Fomos, a este, respeito fortemente inspira- 
dos pelas reflexões seminais de David Lewis (1997).

É bom notar que é possível fazer generalizações razoáveis dos argumentos regressivos erguidos contra aquelas duas teorias metafísicas, bem como em especial dos diagnósticos obtidos a seu respeito, para uma vasta classe de outras teorias metafísicas explicativas dos mesmos fenómenos.

Outra parte do ensaio é dedicada ao célebre argumento regressivo montado por Bertrand Russell contra o nominalismo de semelhança. O tratamento que damos a este argumento é de algum modo diferente e independente daquele que damos aos outros argumentos regressivos relacionais. De facto, utilizando uma distinção aqui muito relevante entre regressões explicativas e regressões eliminativas, concluímos que o argumento de Russell é bem sucedido se for visto como um argumento cujo alvo é exibir, no coração do nominalismo de semelhança, uma regressão ao infinito viciosa. Consideramos também diversas reacções disponíveis na literatura ao argumento de Russell, incluindo a réplica de Gonçalo Rodriguez-Pereyra e duas reacções, em sentido oposto uma da outra, desenvolvidas por Armstrong.

Por uma questão de simplicidade, concentramo-nos no caso da explicação da predicação, considerando sobretudo predicações de primeira ordem. Considerações análogas podem ser feitas relativamente ao caso da explicação da semelhança, coincidência de propriedades ou identidade de natureza.

A estrutura do ensaio é a seguinte. Após algumas considerações preliminares e elementares sobre regressões ao infinito em metafísica (Seç̧ão 1), examinamos a regressão monádica do Realismo Metafísico (Secção 2), a regressão monádica do Nominalismo de Classes (Secção 3), a regressão diádica do Nominalismo de Classes (Secção 4), e, por fim, a regressão diádica do Nominalismo de Semelhança (Secção 5).

\section{Regressões ao infinito em metafísica}

Começamos com algumas considerações introdutórias acerca da noção de regressão ao infinito. 
O que é uma regressão ao infinito? Podemos dizer o seguinte, sem querermos ser muito precisos ou exaustivos. Uma tese, princípio, regra ou explicação conduz a uma regressão ao infinito quando gera uma série de elementos ou estádios que não pode ser parada, que não possui um ponto terminal; ou seja, para qualquer elemento ou estádio da série, é sempre possível encontrar um elemento ou estádio seguinte. Muitas das séries em questão são regressivas no sentido literal do termo, o que significa que cada elemento ou estádio dá origem a um elemento ou estádio que o precede, ad infinitum.

Eis dois exemplos comummente dados de regressões.

- O princípio da causalidade, o princípio de que tudo tem uma causa, ou seja, a ideia de que, para todo o acontecimento ou fenómeno, há um acontecimento ou fenómeno, diferente daquele, que o causa, é muitas vezes visto - talvez não muito correctamente - como dando origem a uma regressão ao infinito (na série de causas).

- O mesmo se pode dizer do resultado da aplicação do mecanismo recursivo característico de diversos operadores frásicos, em especial do operador de verdade, captado na ideia de que prefixar o operador 'É verdade que' a uma frase qualquer $S$ gera uma frase diferente de $S$. Teríamos assim uma série infinita de frases: $S, E$ verdade que $S, E$ verdade que é verdade que $S, E$ verdade que é verdade que é verdade que $S$, e assim por diante.

Como o último exemplo torna manifesto, nem toda a regressão ao infinito é uma regressão viciosa, sendo os casos em questão casos claros de regressões inócuas ou virtuosas. Poderíamos dizer, de forma aproximada, que uma tese, explicação, regra ou princípio conduz a uma regressão ao infinito viciosa ${ }^{2}$ quando, em cada novo estádio ou elemento da série infinita gerada, o facto básico a explicar reaparece, quer de forma manifesta quer de forma meramente implícita. Um exemplo usualmente aduzido de uma regressão viciosa é a teoria holista da justificação, a tese de que verdades só se deixam justificar

\footnotetext{
${ }^{2}$ Uma caracterização de alguma maneira diferente da noção de regressão viciosa é dada em Chisholm 1996: 53. Seguimos, em essência, a caracterização de Armstrong (1989:88-9).
}

Compêndio em Linha de Problemas de Filosofia Analítica 
através de outras verdades. Por outras palavras, para cada proposição verdadeira $p, p$ é justificada se e só se existe uma proposição verdadeira $q$ tal que $q$ é diferente de $p$ e $p$ é verdadeira em virtude de $q$ ser verdadeira, ou a verdade de $p$ depende da verdade de $q$ (ou algo do género). Aparentemente, teríamos aqui uma série infinita de estádios explicativos em cada um dos quais reaparece o facto a explicar, o que é que justifica a verdade de uma dada proposição, acabando assim o facto por nunca vir a ser de facto explicado.

Segundo Armstrong (1989: 11-17; ver também Lewis 1997: 1989), os dois problemas metafísicos tradicionalmente associados ao chamado "problema dos universais" são os seguintes:

- O Problema da Predicação. Como deve ser em geral explicado o facto de um objecto $x$ ter uma propriedade $F$. Em virtude de que é que um $F$ particular (e.g. um certo gato) tem a propriedade $F$ (a propriedade de ser um gato)?

- O Problema da Semelhança. Como deve ser em geral explicado o facto de objectos dados serem semelhantes entre si, serem da mesma natureza ou do mesmo tipo, partilharem uma certa propriedade. Em virtude de que é que os $F$ s (e.g. os gatos) são $F$ s (são gatos)? Em virtude de que é que eles são semelhantes entre si qua gatos? Em virtude de que é que estão agrupados como estão (como gatos)? Em virtude de que é que são do mesmo tipo (o tipo Gato)?

Teorias metafísicas explicativas de ambos os problemas, não apenas o realismo metafísico como também diversas formas de nominalismo, têm sido criticadas com base em argumentos regressivos, alegando-se que as explicações dadas por tais teorias geram regressões viciosas ao infinito e devem por isso ser abandonadas.

O chamado Argumento do Terceiro Homem, que se pode encontrar no diálogo Parménides de Platão (130e-133b), é um desses argumentos. Vale a pena considerá-lo, de modo a podermos instrutivamente contrastar esse argumento com os argumentos regressivos que vamos examinar depois. Trata-se de um argumento contra a explicação realista do Problema da Semelhança em termos de Formas ou Universais. A sua estrutura (reconstruída) é a seguinte. 
Premissa 1: Auto-Predicação das Formas. Os universais, as Formas de Platão, têm eles próprios a propriedade universal que conferem aos particulares que os exemplificam, ou que participam das Formas. Isto justifica-se pelo facto de que, na versão platónica do realismo metafísico, as Formas são paradigmas ou exemplares perfeitos de particulares de um certo género. Ora, um paradigma de um $F$ é ele próprio um $F$ : um paradigma de um felino, por exemplo um tigre da Sibéria, é ele próprio um felino.

Premissa 2: Considere-se a colecção de objectos que consiste em reunir todos os particulares que participam de uma dada forma, digamos $F$, juntamente com a própria forma $F$ da qual eles todos participam. Se $a, b, c$ e $d$ são todos os particulares que participam de $F$, então a colecção $C$ a formar será a seguinte: $\{a, b, c, d, F\}$. Um exemplo seria a colecção $C^{*}$ que consiste em todos os seres humanos juntamente com a forma ou o universal da Humanidade.

Premissa 3: Todos os objectos em $C$ têm uma propriedade em comum, são semelhantes entre si, uma vez que todos eles têm a propriedade $F$, são semelhantes qua $F$ s. Por exemplo, todos os itens em $C *$ têm a propriedade de ser um ser humano: Platão tem-na, Teeteto tem-na, a Humanidade também a tem (pela Premissa 1).

Conclusão 1: Pela explicação proporcionada pelo realismo metafísico para qualquer caso de semelhança ou coincidência de propriedades, vamos precisar de uma nova forma ou universal, digamos $F^{*}$, para explicar em virtude de que é que todos os itens na colecção $C$ de itens, os particulares e a forma $F$, têm a propriedade $F$. Por exemplo, para além dos seres humanos particulares Platão e Teeteto, e da forma da Humanidade, vamos precisar de uma nova forma, digamos a Humanidade*, de um Terceiro Homem, para explicar porque é que aqueles seres humanos particulares e aquela forma têm todos a propriedade de ser um ser humano.

Premissa 4: Forme-se agora uma nova colecção de objectos, digamos $C$, juntando o seguinte: (a) os particulares iniciais $a, b, c, d$; (b) a forma $F$; (c) a nova forma $F^{*}$. Ficamos assim com a colecção 
$C^{\prime}=\left\{a, b, c, d, F, F^{*}\right\}$. Por exemplo, a colecção $C^{\prime} *=\{$ Platão, Teeteto, Humanidade, Humanidade*\}.

Premissa 5: Todos os objectos em C' têm uma propriedade em comum, são semelhantes entre si, uma vez que todos eles têm a propriedade $F$, são semelhantes qua Fs. Todos os itens na colecção $C$ * têm a propriedade de ser um ser humano: Platão e Teeteto têm-na, a Humanidade tem-na, a Humanidade* também (pela Premissa 1).

Conclusão 2: Pela explicação proporcionada pelo realismo metafísico para qualquer caso de semelhança ou coincidência de propriedades, vamos precisar de mais uma nova forma ou universal, digamos $F^{* *}$, para explicar em virtude de que é que todos os itens na colecção $C^{\prime}$ de objectos têm a propriedade $F$. E assim por diante, ad infinitum.

Conclusão Final: Há aqui uma regressão viciosa ao infinito de formas ou universais. Esta conclusão é obtida, segundo o argumento regressivo anti-realista, colocando o seguinte género de dilema ao proponente da explicação realista: (a) ou as sucessivas formas de humanidade são todas do mesmo tipo e nesse caso há uma série infinita de explicações da mesma natureza das semelhanças verificadas, apesar de haver sempre factos novos de semelhança ou coincidência de propriedades a explicar; (b) ou então as sucessivas formas de humanidade são de tipo diferente e nesse caso há uma série infinita de explicações de diferente natureza das semelhanças verificadas e assim factos novos de semelhança ou coincidência de propriedades a explicar. Em qualquer um dos casos, o fenómeno geral a explicar reaparece em cada estádio das séries infinitas geradas, caso em que as regressões são viciosas.

É hoje relativamente consensual que este tipo de argumento não colhe e não mina em geral o realismo metafísico. Na melhor das hipóteses, o argumento ameaça apenas a variedade específica de realismo metafísico de inspiração platónica, o realismo metafísico transcendente. De facto, uma réplica que se oferece naturalmente (Armstrong 1978: 71) consiste em observar que a Premissa 1 do Argumento do Terceiro Homem, a suposição de que todos os universais 
são auto-predicáveis, é errada e deve ser abandonada. E, sem ela, o Argumento do Terceiro Homem não corre. Ora, essa suposição está longe de ser constitutiva da concepção geral associada ao realismo metafísico. Não é de todo necessário que os universais postulados nessa concepção sejam concebidos como paradigmas dos particulares que os exemplificam, ou como exemplares perfeitos, caso em que a motivação para a auto-predicação dos universais se desvanece.

Armstrong (1978: 71) oferece o seguinte argumento no sentido de mostrar que nem todos os universais são auto-predicáveis:

Premissa 1: Uma coisa só é vermelha se for colorida

Premissa 2: $O$ vermelho não é uma coisa colorida, apesar de ser uma cor

Conclusão: $\mathrm{O}$ vermelho não é vermelho

Todavia, mesmo abandonada a suposição da auto-predicação dos universais, o realismo metafísico tem sido ainda alvo de outros argumentos regressivos, bem mais ameaçadores. Examinemos agora um desses argumentos.

\section{A regressão monádica do realismo metafísico}

Consideremos, por uma questão de simplicidade e porque tal é suficiente para a discussão subsequente, os três primeiros estádios da alegada regressão monádica ao infinito gerada pela análise da predicação proposta pelo realismo metafísico. ${ }^{3}$

No Estádio 0 temos as predicações originais a explicar, as predicações de base, proposições como

Estádio 0: Teeteto é sábio

Estádio 0: Teeteto tem a propriedade de ser sábio

\footnotetext{
${ }^{3}$ Seguimos, aproximadamente, a exposição da regressão proporcionada em Loux 1998:35-9. Uma exposição semelhante pode-se encontrar em Quinton 1973: 258-9. Quinton considera que há, mesmo no caso monádico, uma regressão ao infinito viciosa que ameaça quer o realismo metafísico quer qualquer explicação da predicação que assuma a forma de uma análise.
}

Compêndio em Linha de Problemas de Filosofia Analítica 
No Estádio 1 temos as análises realistas dessas predicações, proposições do género Teeteto exemplifica a Sabedoria, em que o termo 'a Sabedoria' designa a propriedade universal, repetível, de ser sábio e o predicado diádico 'exemplifica' designa uma certa relação que o realista metafísico postula como podendo estabelecer-se entre um particular e um universal. Representando aquela propriedade por ' $\lambda x($ Sábio $x)$ ', temos

Estádio 1: Teeteto exemplifica a Sabedoria

Estádio 1: $\mathrm{tE}_{1} \lambda \mathrm{x}$ (Sábio $\left.\mathrm{x}\right)$

$E_{1}$ é aqui a relação que se estabelece entre um particular, $t$ (Teeteto), e um universal monádico, a Sabedoria, quando aquele é um exemplo deste.

Mas, prossegue o argumento regressivo, o Estádio 1 consiste supostamente numa nova predicação, pois parece ter a forma

Teeteto tem a propriedade de exemplificar ${ }_{1}$ a Sabedoria.

Ora, segundo o realismo metafísico, esta predicação tem por sua vez de ser analisada, como qualquer outra. Chegamos assim ao Estádio 2 , dando a análise origem àquilo que parece ser ainda outra predicação

Estádio 2: Teeteto exemplifica ${ }_{2}$ Exemplificação ${ }_{1}$ da Sabedoria

Estádio 2: $\mathrm{t}_{2} \lambda \mathrm{y}\left(\mathrm{y} \mathrm{E}_{1} \lambda \mathrm{x}(\right.$ Sábio $\left.\mathrm{x})\right)$

$E_{2}$ é aqui a relação que se estabelece entre um particular, Teeteto, e um universal monádico, a Exemplificação, da Sabedoria, quando aquele é um exemplo deste.

Consideremos agora a suposta predicação contida no Estádio 2

Teeteto tem a propriedade de exemplificar ${ }_{2}$ a Exemplificação ${ }_{1}$ da Sabedoria

Esta tem, por sua vez, de ser analisada, no Estádio 3, em termos daquilo que parece ser uma nova predicação

Estádio 3: Teeteto exemplifica ${ }_{3}$ Exemplificação ${ }_{2}$ da Exemplificação da Sabedoria 
Estádio 3: $\mathrm{tE}_{3} \lambda \mathrm{y}\left(\mathrm{y} \mathrm{E}_{2} \lambda_{\mathrm{z}}\left(\mathrm{z} \mathrm{E}_{1} \lambda \mathrm{x}(\right.\right.$ Sábio $\left.\left.\mathrm{x})\right)\right)$

$E_{3}$ é aqui a relação que se estabelece entre um particular, Teeteto, e um universal monádico, a Exemplificação, da Exemplificação, da Sabedoria, quando aquele é um exemplo deste.

E assim por diante, dando aparentemente origem a uma série infinita de predicações de exemplificação.

$\mathrm{O}$ argumento regressivo contra o Realismo Metafísico procede então do seguinte modo. Concentremo-nos nos Estádios 1 e 2, observando que considerações análogas podem ser feitas com respeito a qualquer um dos pares de estádios subsequentes da série.

Suponhamos, para começar, que as relações de exemplificação presentes no Estádio 2, uma das quais é herdada do Estádio 1, são da mesma natureza, são o mesmo tipo de universal relacional. Por outras palavras, suponhamos que Exemplificação ${ }_{1}\left(\mathrm{E}_{1}\right)$ e Exemplificação $\left(\mathrm{E}_{2}\right)$ são do mesmo género. Segue-se que as propriedades $A$ Exemplificação, da Sabedoria, $\lambda_{y}\left(y E_{1} \lambda_{x}(\right.$ Sábio x $\left.)\right)$, e $A$ Exemplificação ${ }_{2}$ da Exemplificação da Sabedoria, $\lambda_{z} E_{2} \lambda_{y}\left(y E_{1} \lambda_{x}(\right.$ Sábio $\left.x)\right)$, são propriedades universais da mesma natureza. Mas então a análise realista é circular, pois o facto a analisar, a predicação no Estádio 1, seria analisado em termos de um facto do mesmo género, a predicação no Estádio 2. Estar-se-ia assim a explicar o mesmo em termos do mesmo, indefinidamente.

Suponhamos, por outro lado, que as exemplificações em questão são de tipo diferente, que são universais relacionais distintos em género. Segue-se que as propriedades $A$ Exemplificação da Sabedoria, $\lambda_{y}(y$ $E_{1} \lambda_{x}\left(\right.$ Sábio x)), e $A$ Exemplificação ${ }_{2}$ da Exemplificação da Sabedoria, $\lambda_{z}$ $E_{2} \lambda_{y}\left(y E_{1} \lambda_{x}(\right.$ Sábio $\left.x)\right)$, são propriedades universais de diferente natureza. Mas então haveria uma multiplicação ao infinito de universais monádicos de exemplificação: A Exemplificação ${ }_{1}$ da Sabedoria, A Exemplificação ${ }_{2}$ da Exemplificação da Sabedoria, A Exemplificação ${ }_{3}$ da Exemplificação ${ }_{2}$ da Exemplificação da Sabedoria, e assim por diante.

O aparente dilema para o realismo metafísico é, pois, o seguinte. $\mathrm{Ou}$ a análise realista não peca pela falta de economia relativamente aos universais invocados (havendo um único tipo de propriedades universais de exemplificação), mas cada um dos seus estádios contém um círculo explicativo, explicando o mesmo em termos do mesmo, indefinidamente. Ou então a análise realista peca pela falta de economia relativamente aos universais invocados (há infinitamente muitos 
universais de exemplificação), reaparecendo em todo o caso o facto geral a explicar, a predicação, em cada um dos seus estádios. Em qualquer caso, estaríamos perante uma regressão ao infinito viciosa.

Como é que se deve avaliar este género de argumento regressivo?

A réplica central que queremos proporcionar é a de que é fortemente plausível pensar que as sucessivas propriedades de exemplificação, mais do que serem da mesma natureza, são na realidade uma e a mesma propriedade universal.

De facto, a pretensão de que se trata de relações diferentes não tem qualquer motivação. Note-se que a segunda propriedade de exemplificação da sabedoria, a que é introduzida no Estádio 2, não é atribuível, como parece ser linguisticamente sugerido, à primeira propriedade de exemplificação da sabedoria, a introduzida no Estádio 1, mas antes a particulares (aliás, precisamente aos particulares aos quais esta última é aplicável). Não se trata, pois, de uma propriedade de segunda ordem, uma propriedade de propriedades, mas de uma propriedade de primeira ordem, uma propriedade cujos exemplos são particulares ou indivíduos. Uma coisa é a propriedade que um indivíduo $x$ tem de ser um exemplo de uma dada propriedade, da propriedade de ser um $F$

$$
\lambda x(\mathrm{xE} \lambda \mathrm{yFy})
$$

Esta é uma propriedade de primeira ordem. Outra coisa é a propriedade que uma propriedade de primeira ordem, a propriedade de ser um $F$, possui quando tem algum particular como exemplo, quando é exemplificada por algo

$$
\lambda \mathrm{z}(\exists \mathrm{y} \text { yEz } \wedge \mathrm{z}=\lambda \mathrm{xFx})
$$

Esta é uma propriedade de segunda ordem.

Ora, a propriedade de exemplificar a exemplificação da sabedoria é como a primeira propriedade atrás introduzida, não como a segunda. Por conseguinte, aquela que parece ser a motivação central para distinguir entre diversas relações e diversas propriedades de exemplificação, quanto à sua natureza ou tipo, não está disponível. Mas, se assim é, então o universal monádico $A$ Exemplificação da Exemplificação, da Sabedoria deixa-se simplesmente reduzir ao universal monádico A Exemplificação da Sabedoria. E o mesmo sucederia com todos os universais monádicos de exemplificação subsequentes, os quais se 
deixariam reduzir aos dos estádios imediatamente precedentes e, em última análise, àquele universal monádico de partida.

De notar que, para além do facto de serem da mesma ordem, há ainda outra razão sólida para considerar tais propriedades universais de exemplificação como sendo uma e a mesma propriedade: trata-se de propriedades, não apenas co-extensivas, mas necessariamente co- extensivas (ver Apêndice).

Assim sendo, o prefixo 'A exemplificação da' tem um efeito semântico redundante (ver os detalhes no Apêndice), um efeito análogo ao do operador frásico 'É verdade que'. Tal como 'A exemplificação da exemplificação da sabedoria' se deixa simplificar como 'A exemplificação da sabedoria', também 'É verdade que é verdade que neva' se deixa simplificar como 'É verdade que neva'. Dizer que Teeteto exemplifica a Exemplificação da Sabedoria é dizer que Teeteto é um exemplo daquela propriedade universal cujos exemplos são as pessoas sábias, o que equivale afinal a dizer que Teeteto exemplifica a Sabedoria (assumindo, claro, que todas estas exemplificações são uma e a mesma coisa).

Todavia, poderia ainda argumentar o proponente do argumento regressivo, o círculo explicativo torna-se, ainda assim, óbvio. A nossa pergunta no Estádio 1 era

Em virtude de que é que Teeteto exemplifica a Sabedoria?

A resposta realista que é dada no Estádio 2 é

Em virtude de Teeteto exemplificar a exemplificação da Sabedoria

Mas, como vimos, este último facto não consiste senão no facto de Teeteto exemplificar a Sabedoria. Logo, aquilo que no fundo nos está a ser dito é que Teeteto exemplifica a Sabedoria porque... exemplifica a Sabedoria!

Como é que o realista metafísico poderia replicar? A melhor maneira de o fazer consiste em combinar as seguintes duas pretensões: (a) Não há qualquer círculo explicativo na progressão do Estádio 1 para o Estádio 2; (b) O prefixo 'A exemplificação de' é semanticamente redundante. O ponto é que, dada a pretensão (a), conceder (b) não traz qualquer problema. 
Vejamos, primeiro, o que é que o realista metafísico tem em mente com (a). Só há um círculo explicativo quando existe um projecto explícito de análise de uma certa noção ou facto. Ora, as noções ou os factos envolvidos no Estádio 1 não são noções ou factos para os quais a teoria do realismo metafísico esteja obrigada a proporcionar uma análise. Com efeito, temos de distinguir entre as seguintes duas coisas. De um lado, temos predicações do género

Sócrates é sábio

Sócrates tem a propriedade de ser sábio

Estas predicações situam-se no Estádio 0. Do outro lado, temos alegadas predicações do género

Sócrates exemplifica a Sabedoria

Sócrates tem a propriedade de exemplificar a Sabedoria

Estas aparentes predicações situam-se no Estádio 1.

As primeiras são predicações genuínas (do ponto de vista da teoria), factos que o realismo tem inegavelmente de analisar. Tal análise é justamente dada no Estádio 1, através de factos do segundo género antes descrito. Mas o realista não está de todo obrigado a reconhecer estes últimos factos como consistindo em predicações genuínas (do ponto de vista da teoria), como factos que têm o mesmo estatuto dos factos do estádio 0 , não estando assim obrigado a proporcionar qualquer análise para eles. O realista está obrigado a explicar as predicações do Estádio 0, mas isso não o obriga a explicar toda e qualquer aparente predicação. Em particular, o realista é livre de se recusar a explicar aparentes predicações expressas por meio de um predicado de exemplificação que tem o estatuto de predicado primitivo na teoria por ele proposta. Deste modo, o argumento regressivo monádico contra o realismo metafísico é inócuo.

E, como vamos ver a seguir, considerações análogas podem ser feitas pari passu relativamente a qualquer outra teoria metafísica explicativa da predicação, pelo menos se tal teoria assumir a forma de uma análise, ou seja, a forma de uma eliminação de factos dados, relativos a predicações ou semelhanças, em termos de factos mais primitivos do ponto de vista da teoria. (Temos vindo a supor, sem 
qualquer discussão, que as teorias metafísicas da predicação e da semelhança tomam a forma de análises; uma crítica de tal suposição encontra-se em Lewis 1997).

\section{A regressão monádica do nominalismo de classes}

É muitas vezes alegado que as explicações proporcionadas pelo nominalismo de classes para os problemas da semelhança e da predicação são fortemente suspeitas de envolver regressões viciosas ao infinito: os mesmos factos, as semelhanças ou as predicações, são sucessivamente reintroduzidos em cada estádio das séries infinitas explicativas geradas pela teoria, acabando por nunca vir a ser explicados.

O nominalismo de classes é, resumidamente, o ponto de vista de que propriedades não são entidades universais, repetíveis, mas devem ser identificadas com, ou reduzidas a, certos particulares abstractos, classes ou conjuntos, entidades irrepetíveis. Consideremos o padrão geral de explicação da predicação tipicamente proporcionado pelo nominalismo de classes.

(*) Um particular $x$ tem a propriedade de ser $F$ porque $x$ pertence à classe $\operatorname{dos} F_{\mathrm{S}}$

Raciocinando sobre um exemplo, comecemos com uma predicação monádica simples como

Rover é um cão

Rover tem a propriedade de ser um cão

Este constitui, digamos, o Estádio 0 da série explicativa, o qual consiste no facto de partida, o facto para o qual a teoria metafísica é supostamente obrigada a propor uma explicação.

Segundo o nominalismo de classes, factos como aquele são explicados em termos de novos factos, factos mais básicos ou mais primitivos do que aquele, como (no nosso exemplo) o seguinte

Rover pertence à classe dos cães

Todavia, de acordo com o proponente do argumento regressivo, temos aqui uma nova predicação monádica, um novo facto essencialmente da mesma natureza daquele que ocorre no Estádio 0, desig- 
nadamente

Rover tem a propriedade de pertencer à classe das coisas que são cães

Este constitui o Estádio 1 da série explicativa. Como se trata alegadamente de uma predicação, o nominalismo de classes parece estar obrigado a explicá-la da mesma maneira, de acordo com o mesmo padrão, em termos de um novo facto, mais básico do que o facto no Estádio 1. Esse novo facto seria então do seguinte género

Rover pertence à classe das coisas que pertencem à classe das coisas que são cães

Ora, o argumento regressivo prossegue olhando para este último facto como consistindo numa nova predicação, um novo facto da mesma natureza daquele que ocorre no Estádio 1, designadamente

Rover tem a propriedade de pertencer à classe das coisas que pertencem à classe das coisas que são cães

Este constitui o Estádio 2 da série explicativa. Como se trata alegadamente de uma predicação, o nominalismo de classes parece estar obrigado a explicá-la da mesma maneira, de acordo com o mesmo padrão, em termos de um novo facto, mais básico do que o facto no Estádio 2. Esse novo facto seria do seguinte género

Rover pertence à classe das coisas que pertencem à classe das coisas que pertencem à classe das coisas que são cães

Ora, o argumento regressivo prossegue olhando para este último facto como consistindo numa nova predicação, um novo facto da mesma natureza daquele que ocorre no Estádio 2, designadamente

Rover tem a propriedade de pertencer à classe das coisas que pertencem à classe das coisas que pertencem à classe das coisas que são cães

Este constitui o Estádio 3 da série explicativa. Como se trata alegadamente de uma predicação, o nominalismo de classes parece estar obrigado a explicá-la da mesma maneira, de acordo com o mesmo padrão, em termos de um novo facto, mais básico do que o facto no Estádio 3. Esse novo facto seria do seguinte género 
Rover pertence à classe das coisas que pertencem à classe das coisas que pertencem à classe das coisas que pertencem à classe das coisas que são cães

Mas, aparentemente, teríamos aqui uma nova predicação, a qual teria de ser explicada pelo nominalismo de classes em termos de um novo facto de pertença a uma classe. E assim por diante, ad infinitum.

Tudo parece indicar que estamos perante uma regressão ao infinito, uma vez que é sempre possível gerar, para cada caso ou estádio, um caso ou estádio seguinte, sendo assim gerada uma série infinita de explicações. Por outro lado, a regressão ao infinito parece ser viciosa, uma vez que, em cada caso ou estádio, o conceito a analisar, a predicação, reaparece. Qualquer facto de pertença a uma classe por parte de um particular, Rover, é aparentemente uma predicação de algo, nomeadamente da propriedade de pertencer a essa classe, ao particular em questão. Por conseguinte, o conceito a analisar ou explicar, o de predicação, nunca é de facto analisado ou explicado pela teoria metafísica do nominalismo de classes. E considerações análogas valem para a análise proporcionada pelo nominalismo de classes para o problema da semelhança ou coincidência de propriedades.

Como é que se deve reagir a este género de argumento regressivo?

Julgo que de um modo essencialmente semelhante àquele com o qual avaliámos, na Secção 2, o argumento regressivo contra o realismo metafísico.

A réplica central que queremos proporcionar é a de que é possível verificar, após alguma reflexão, que as classes de objectos introduzidas nos diversos estádios sucessivos da série de explicações se deixam na realidade reduzir, à luz do axioma da extensionalidade para classes ou conjuntos, a uma única classe de objectos, no caso simplesmente a classe das coisas que são cães. Por conseguinte, só haveria na verdade, na melhor das hipóteses, uma única predicação, que consiste no facto de Rover pertencer à classe das coisas que são cães. (Para além disso, note-se que o nominalista de classes teria o direito de se recusar a analisar mais este facto. Basta-lhe analisar o facto de partida, o facto de Rover ser um cão ou ter a propriedade de ser um cão; e isto ele certamente faz.)

Consequentemente, rigorosamente falando, nem sequer estamos perante uma regressão ao infinito genuína, muito menos uma re- 
gressão viciosa. Isto pela simples razão de que nem sequer uma série infinita de explicações ou estádios explicativos é de facto gerada. A série tem apenas um ponto, o Estádio 1, pois todos os outros aparentes estádios se deixam reduzir ao Estádio 1.

Para vermos que as classes nos diversos estádios são idênticas, basta raciocinar para o caso dos estádios 1,2 e 3 e constatar que o mesmo se aplica às classes introduzidas em quaisquer dos estádios subsequentes.

De facto, a classe no Estádio 1, ou seja, a classe das coisas que são cães

$\{x:$ x é um cão $\}$

é, pelo axioma da extensionalidade, a mesma classe do que a classe no Estádio 2, ou seja, a classe das coisas que pertencem à classe das coisas que são cães

$$
\{\mathrm{y}: \mathrm{y} \in\{\mathrm{x}: \mathrm{x} \text { é um cão }\}\}
$$

E esta classe é por sua vez a mesma classe do que a classe introduzida no Estádio 3, ou seja, a classe das coisas que pertencem à classe das coisas que pertencem à classe das coisas que são cães

$$
\{\mathrm{z}: \mathrm{z} \in\{\mathrm{y}: \mathrm{y} \in\{\mathrm{x}: \mathrm{x} \text { é um cão }\}\}
$$

E assim por diante.

Há apenas a ilusão de as sucessivas classes de coisas serem classes distintas. Mas trata-se de uma mera ilusão linguística, causada pelas formas de expressão utilizadas.

Armstrong expõe a regressão monádica ou objectual do nominalismo de classes de um modo diferente da nossa reconstrução acima (1978: 41-2). A versão de Armstrong é, a nosso ver, menos interessante e tem consequências de natureza distinta do ponto de vista do seu diagnóstico avaliativo.

Consideremos o exemplo anterior e a análise proporcionada pelo nominalismo de classes para as predicações originais

Rover é um cão

Rover tem a propriedade de ser um cão em termos da proposição 
Rover pertence à classe dos cães

A regressão objectual de Armstrong é então construída da seguinte maneira. Olhemos para a classe introduzida no primeiro estádio da análise nominalista, no exemplo a classe dos cães. Armstrong introduz uma predicação aparentemente genuína acerca dessa classe, designadamente a seguinte

(1) A classe dos cães é a classe dos cães

(1) A classe dos cães tem a propriedade de ser a classe dos cães

Esta propriedade, a de ser a classe dos cães, é certamente constitutiva da classe dos cães, algo que a classe dos cães tem em virtude da sua natureza interna. A predicação em questão deve, por conseguinte, ser objecto de análise, o que o nominalismo de classes terá de fazer em termos da proposição

(2) A classe dos cães pertence à classe-unidade da classe dos cães

Mas esta proposição dá por sua vez origem a uma nova predicação

(3) A classe dos cães tem a propriedade de pertencer à classeunidade da classe dos cães

a qual é analisável em termos da proposição

(4) A classe dos cães pertence à classe-unidade da classe-unidade da classe dos cães.

E assim por diante, ad infinitum.

Armstrong alega que este argumento regressivo pode ser contrariado observando que a regressão aí envolvida é apenas aparente. Com efeito, a regressão não pode ser construída em virtude do facto de a propriedade introduzida em (1) não estar associada a um tipo de coisas, a uma entidade repetível, pois é uma propriedade com um único exemplo (há uma e uma só classe dos cães). Armstrong parece assim supor que uma condição necessária para haver uma regressão genuína, ou pelo menos para haver uma regressão ao infinito viciosa, 
é haver uma reintrodução de um novo tipo de coisas em cada estádio da série infinita explicativa.

A nossa reacção a esta versão de Armstrong da regressão monádica do nominalismo de classes é a seguinte.

Em primeiro lugar, e em contraste com a nossa reconstrução da regressão monádica, é de facto gerada neste caso uma série infinita de entidades. Mas trata-se de uma série manifestamente não problemática e inócua do ponto de vista da habitual teoria das classes ou dos conjuntos, pois é uma série gerada por um mecanismo iterativo claro e perfeitamente em ordem. Dado um objecto, a classe dos cães, é possível formar a sua classe-unidade, a classe cujo único elemento é esse objecto, a classe-unidade da classe dos cães. E, dada esta classe, é possível formar do mesmo modo a sua classe-unidade, a classe cujo único elemento é a classe-unidade da classe dos cães, a classe-unidade da classe-unidade da classe dos cães. E assim por diante. Não parece haver nada de problemático nestas séries.

Em segundo lugar, e bem mais importante, há que observar o seguinte. Apesar de, tal como formulada por Armstrong, a regressão não ser viciosa, pois não há nela uma multiplicação de tipos (concedamos, para efeitos de argumentação, a suposição de Armstrong aqui utilizada), é no entanto possível reconstrui-la razoavelmente de modo a gerar uma regressão aparentemente viciosa. Por exemplo, poderíamos substituir (1) pela seguinte proposição

(1)' A classe dos cães é uma classe que contém cães como elementos

(1)' A classe dos cães tem a propriedade de ser uma classe que contém cães como elementos

Esta propriedade, a de ser uma classe que contém cães como elementos, é certamente constitutiva da classe dos cães, algo que a classe tem em virtude da sua natureza interna. A predicação em questão tem, por conseguinte, de ser objecto de análise, o que o nominalismo de classes terá de fazer em termos da proposição

(2)' A classe dos cães pertence à classe cujos elementos são classes que contêm cães como elementos 
E esta proposição dá por sua vez origem a uma nova predicação

(3)' A classe dos cães tem a propriedade de pertencer à classe cujos elementos são classes que contêm cães como elementos

a qual é analisada em termos da proposição

(4)' A classe dos cães pertence à classe cujos elementos são classes cujos elementos são classes que contêm cães como elementos

E assim por diante, ad infinitum.

Note-se agora que a propriedade introduzida em (1)' está, desta vez, associada a um tipo de coisas, a uma entidade repetível, pois é uma propriedade com mais do que dois exemplos (há muitas classes de coisas entre cujos elementos estão cães: a classe dos mamíferos, a classe dos animais domésticos, a classe dos cocker spaniel, etc.). Teríamos neste caso uma regressão viciosa de explicações: nunca nos conseguiríamos livrar de tipos de coisas. Aquilo que o nominalismo de classes é suposto explicar, tipos de coisas em termos de classes de coisas, acabaria por nunca vir a ser explicado, sendo os tipos sempre reintroduzidos em cada estádio explicativo.

Julgamos que o diagnóstico apropriado para este novo argumento regressivo, a maneira mais adequada de travar a regressão, é utilizar relativamente a ele o mesmo género de avaliação que utilizámos a respeito do argumento regressivo monádico contra o realismo metafísico e que iremos utilizar em seguida para os casos das regressões relacionais ou diádicas do nominalismo de classes e, por implicação, do realismo metafísico.

As noções ou os factos envolvidos em proposições como (2)' não são noções ou factos para os quais a teoria do nominalismo de classes esteja obrigada a proporcionar uma análise, pelo que não se deve olhar para (2)' como dando origem a uma nova predicação, (3)'. Com efeito, temos de distinguir entre as seguintes duas coisas. De um lado, predicações do género

A classe dos cães é uma classe que contém cães como elementos 
A classe dos cães tem a propriedade de ser uma classe que contém cães como elementos

Estas predicações situam-se, suponhamos, no Estádio 0. Do outro, alegadas predicações do género

A classe dos cães pertence à classe cujos elementos são as classes que contêm cães como elementos

A classe dos cães tem a propriedade de pertencer à classe cujos elementos são as classes que contêm cães como elementos

Estas aparentes predicações situam-se no Estádio 1. As primeiras são predicações genuínas, factos que o nominalismo de classes tem inegavelmente de analisar. Tal análise é justamente dada no Estádio 1, através de factos do segundo género antes descrito.

Mas o nominalista de classes não está de todo obrigado a reconhecer estes últimos factos como consistindo em predicações genuínas (do ponto de vista da teoria), como factos que têm o mesmo estatuto dos factos do estádio 0 , não estando assim obrigado a proporcionar qualquer análise para eles. O nominalista de classes está obrigado a explicar as predicações do Estádio 0, mas isso não o obriga a explicar toda e qualquer aparente predicação. Em particular, ele é livre de se recusar a explicar aparentes predicações expressas por meio de um predicado de pertença que tem o estatuto de predicado primitivo na teoria por ele proposta. Deste modo, o argumento regressivo monádico contra o nominalismo de classes, nesta reconstrução da versão proposta por Armstrong, é igualmente ineficaz.

Há três maneiras de olhar para tais alegadas predicações, por exemplo as proposições do Estádio 2'.

(a) Tomá-las como peudo-predicações, ou seja, como proposições que só aparentemente são predicativas mas que não o são na realidade (do ponto de vista da teoria, naturalmente). Como não se trata, no fundo, de predicações, a teoria não estaria obrigada a acomodar tais factos. Esta opção tem a desvantagem de recorrer a uma noção de pseudo-predicação, e a uma distinção entre predicações genuínas e pseudo-predicações, que pode ser vista como suspeita de não ter contornos claros. 
(b) Tomá-las como predicações que não precisam de qualquer explicação, seja através de uma análise seja de qualquer outra forma. Eis alguns exemplos de predicações que muitas teorias metafísicas poderiam considerar como factos não mooreanos, factos que não exigem qualquer explicação.

Neymar tem a propriedade de ser um mau jogador se $2+2=5$

Neymar tem a propriedade de ser auto-idêntico

Neymar tem a propriedade de não ter estado vivo em 1817

Neymar tem a propriedade de não ser um número par

(c) Finalmente, tomá-las como predicações que precisam de uma explicação, mas notar que tal explicação consiste simplesmente no seu reconhecimento como factos primitivos, insusceptíveis de análise, do ponto de vista da teoria. No caso do Nominalismo de classes, exemplos são proposições expressas usando o vocabulário primitivo da própria teoria

Neymar tem a propriedade de pertencer à classe dos seres humanos

No caso do Realismo Metafísico Aristotélico, exemplos são dados em proposições expressas usando o vocabulário primitivo da teoria

Neymar é um membro da espécie animal Homo Sapiens Sapiens

\section{A regressão relacional do nominalismo de classes}

Consideremos agora outro género de argumento regressivo contra o nominalismo de classes, o qual se centra no caso de predicações diádicas. O género de diagnóstico negativo que iremos fazer destes argumentos estende-se por analogia aos argumentos regressivos semelhantes erguidos contra o realismo metafísico, os quais nos vamos assim dispensar de considerar.

Comecemos por observar que o nominalismo de classes analisa predicações diádicas em geral, por exemplo proposições como

Sócrates é amigo de Teeteto 
Sócrates está na relação ser amigo de com Teeteto

em termos de pertenças de pares ordenados de objectos a classes cujos elementos são pares ordenados de objectos. Assim, aquela predicação relacional seria analisada em termos do facto seguinte, um facto acerca da pertença de um par ordenado a uma classe de pares ordenados

$<$ Sócrates, Teeteto $>\in\{<\mathrm{x}, \mathrm{y}\rangle: \mathrm{x}$ é amigo de $\mathrm{y}\}$

Posto isto, consideremos de novo os factos de partida a explicar, ou seja, as predicações monádicas que constituem o Estádio $\mathbf{0}$ das séries explicativas anteriores. Utilizemos para o efeito o exemplo anterior

Rover é um cão

Rover tem a propriedade de ser um cão

De acordo com o nominalismo de classes, no Estádio 1 ficamos com factos mais básicos acerca da pertença de particulares a classes, factos do género antes mencionado

Rover pertence à classe das coisas que são cães

Todavia, o proponente do argumento regressivo relacional alega agora que o facto de um objecto pertencer a uma classe, o facto de Rover pertencer à classe dos cães, é uma predicação diádica como qualquer outra, na qual uma relação, a relação de pertença, se estabelece entre um objecto, um indivíduo, Rover, e outro objecto, uma classe de indivíduos, a classe dos cães. Exactamente como o facto de Sócrates ser amigo de Teeteto se deixa analisar como uma predicação diádica na qual uma relação, a relação de amizade, se estabelece entre um objecto, um indivíduo, Sócrates, e outro objecto, outro indivíduo, Teeteto. Teríamos assim uma proposição ou facto relacional como

Rover está na relação de pertença com a classe das coisas que são cães

Rover $\in\{x:$ x é um cão $\}$

Factos como estes constituiriam o Estádio 2 da série explicativa. Ora, como se trata supostamente de predicações, estes últimos factos, factos acerca da pertença de objectos a classes de objectos, care- 
cem de uma explicação à luz do padrão explicativo do nominalismo de classes para predicações diádicas em geral. Segundo o nominalismo de classes, factos do género são explicados em termos de novos factos, factos mais básicos ou mais primitivos do que aquele, no nosso caso o seguinte facto (assumindo como ponto de partida um universo de indivíduos)

O par ordenado de objectos $<$ Rover, A classe dos cães $>$ pertence à classe de todos os pares ordenados de indivíduos e classes de indivíduos ${ }^{4}$ tais que aqueles são elementos destas

$<$ Rover, A classe dos cães $>\in\{<\mathrm{x}, \mathrm{y}\rangle$ : $\mathrm{x}$ é um indivíduo \& y é uma classe de indivíduos \& $\mathrm{x} \in \mathrm{y}\}$

Note-se que, enquanto as classes invocadas no Estádio 1 se reduzem a classes de indivíduos, no Estádio 2 temos duas classes: de um lado, um par ordenado de um indivíduo e uma classe de indivíduos, o qual é uma classe de classes de indivíduos (pois pares ordenados são classes de objectos); do outro lado, uma classe de pares ordenados de indivíduos e classes às quais eles pertencem, a qual é uma classe de classes de classes de indivíduos.

Todavia, de acordo com o proponente do argumento regressivo relacional, o Estádio 2 dá origem a uma nova predicação relacional, um novo facto da mesma natureza daquele que ocorre nesse estádio, designadamente o seguinte

O par ordenado < Rover, A classe dos cães $>$ está na relação de pertença com a classe de todos os pares ordenados de indivíduos e classes de indivíduos tais que aqueles são elementos destas

Estes factos constituem o Estádio 3 da série explicativa. Como se trata alegadamente de predicações diádicas, o nominalismo de classes parece estar obrigado a explicá-los da mesma maneira, de acordo com o mesmo padrão, em termos de um novo facto, mais básico do

\footnotetext{
${ }^{4}$ Se esta restrição a classes cujos elementos são indivíduos não fosse aqui feita, nem sequer a série infinita explicativa poderia ser gerada, já que um predicado diádico irrestrito de pertença não tem, por razões conhecidas, sequer uma extensão, não havendo assim qualquer fundamento para aplicar o esquema explicativo do nominalismo de classes às aparentes predicações diádicas em questão. Estamos gratos a Dirk Greimman por nos ter alertado para este facto.
}

Compêndio em Linha de Problemas de Filosofia Analítica 
que o facto no Estádio 3. Esse novo facto seria do seguinte género:

O par ordenado de objectos que consiste no par ordenado $<$ Rover, A classe dos cães $>$ e na classe de todos os pares ordenados de indivíduos e classes de indivíduos tais que aqueles são elementos destas pertence à classe de todos os pares ordenados que consistem em, de um lado, (a) pares de indivíduos e classes de indivíduos; (b) a classe de todos os pares de indivíduos e classes de indivíduos às quais eles pertencem, e, do outro lado, a classe à qual todos os pares ordenados como (a),(b) pertencem

$<<$ Rover, A classe dos cães $>,\{<\mathrm{x}, \mathrm{y}\rangle$ : $\mathrm{x}$ é um indivíduo \& y é uma classe de indivíduos $\& \mathrm{x} \in \mathrm{y}\}>\in\{<\mathrm{z}, \mathrm{w}>$ : $\mathrm{z}$ é um par ordenado de (a) pares de indivíduos e classes de indivíduos; (b)a classe de todos os pares de indivíduos e classes de indivíduos às quais eles pertencem \& w é uma classe à qual todos os pares ordenados como z pertencem \& $\mathrm{z} \in \mathrm{w}\}$

No Estádio 3 temos duas classes: de um lado, uma classe de pares ordenados de indivíduos e classes de indivíduos às quais eles pertencem, a qual é uma classe de classes de classes de indivíduos (esta classe vem do Estádio 2); do outro, uma classe de classes de classes de classes de indivíduos.

Mas aquela proposição, argumenta-se, seria ainda uma predicação relacional de pertença que carece de análise pelo nominalismo de classes de acordo com o mesmo padrão. E assim por diante, ad infinitum.

Como é que se pode avaliar este argumento?

Note-se que a analogia com as réplicas dadas aos argumentos regressivos para o caso monádico perde-se parcialmente, como vamos ver, no caso relacional, pelo que as coisas são aqui um pouco mais complexas.

Em primeiro lugar, estamos na verdade perante uma regressão ao infinito genuína no caso relacional. Para cada estádio explicativo, é sempre possível gerar um estádio explicativo seguinte diferente daquele, pois temos uma predicação diádica de pertença nova que parece exigir uma explicação. No caso relacional, não é difícil verificar que as alegadas predicações diádicas, as sucessivas afirmações de pertença, são diferentes entre si, pois os objectos, as classes, que 
estão naquela relação são diferentes entre si nos diversos estádios da série. Por outras palavras, os relata da relação de pertença num dado estádio são sempre pares ordenados de objectos ou classes de pares ordenados de objectos distintos dos pares ou classes no estádio imediatamente precedente. Por conseguinte, a réplica que demos ao argumento regressivo monádico, de que nem sequer uma regressão infinita pode de facto ser construída, não colhe neste caso.

Todavia, esta observação pode ser mitigada de duas maneiras. Por um lado, as séries infinitas de classes e predicações de pertença aí envolvidas não parecem ter muito de problemático, uma vez que são geradas através da aplicação de uma regra ou mecanismo recursivo conhecido e em ordem. Por outro lado, não é razoável supor que as predicações de pertença em cada estádio da série infinita sejam de tipos diferentes, i.e. que, à medida que se sobe de nível, a relação de pertença aí envolvida é de uma natureza diferente da que está envolvida no nível precedente. ${ }^{5}$ De facto, tal equivaleria a supor que as três proposições seguintes, por exemplo, envolvem relações de pertença de tipo diferente, o que não é de todo plausível:

$$
\begin{aligned}
& \text { Sócrates } \in\{\text { Sócrates }\} \\
& \{\text { Sócrates }\} \in\{\{\text { Sócrates }\}\} \\
& \{\{\text { Sócrates }\}\} \in\{\{\{\text { Sócrates }\}\}\}
\end{aligned}
$$

Em segundo lugar, a regressão ao infinito parece ser em todo o caso viciosa, uma vez que, em cada estádio, o conceito a analisar, o de predicação relacional, parece reaparecer. Aparentemente, qualquer pertença de algo, um dado par ordenado de objectos, a uma certa classe de pares ordenados de objectos, é uma predicação de uma relação, a relação de pertença, ao par ordenado de objectos que consiste no par ordenado de objectos dado e na classe de pares ordenados de objectos em questão.

Não obstante, a construção da série infinita de explicações pode ser parada no Estádio 1, basicamente à luz do mesmo padrão de análise que utilizámos antes para o caso monádico, quer em relação ao

\footnotetext{
${ }^{5} \mathrm{O}$ resultado análogo para o caso da regressão diádica do realismo metafísico não é completamente claro, mas ignoramos aqui o problema.
} 
nominalismo de classes quer em relação ao realismo metafísico.

Com efeito, os factos no Estádio 1 podem ser vistos, não como mais predicações (diádicas) a explicar, mas como o terminus da explicação, como constituindo factos primitivos ou irredutíveis do ponto de vista do nominalismo de classes, no sentido de factos cuja verificação não se deve à verificação de qualquer outro tipo de factos. $\mathrm{O}$ nominalista de classes não está obrigado a olhar para tais factos como consistindo em predicações diádicas genuínas (do ponto de vista da teoria), como factos que têm o mesmo estatuto dos factos do estádio 0 , não estando assim obrigado a proporcionar qualquer análise para eles. O nominalista de classes está obrigado a explicar as predicações diádicas do Estádio 0, mas isso não o obriga a explicar toda e qualquer aparente predicação. Em particular, ele é livre de se recusar a explicar aparentes predicações expressas por meio de um predicado de pertença que tem o estatuto de predicado primitivo na teoria por ele proposta.

O nominalista de classes poderia declarar tais predicações diádicas como meramente aparentes através de uma das três maneiras antes ${ }^{6}$ identificadas aquando da discussão da alegada regressão monádica do nominalismo de classes. Deste modo, o argumento regressivo diádico contra o nominalismo de classes é igualmente ineficaz.

\section{Regressão ao infinito no nominalismo de semelhança}

Também o nominalismo de semelhança incorre na suspeita de envolver regressões viciosas ao infinito. Essa forma de nominalismo foi sugerida por vários autores modernos, mas foi somente desenvolvida plenamente por Gonzalo Rodriguez-Pereyra (2002).

Segundo a explicação do nominalismo de semelhança, um particular não se assemelha a outro particular porque ambos exemplificam a mesma propriedade, mas o oposto: eles exemplificam uma propriedade em virtude de serem semelhantes. A semelhança, nessa teoria, é considerada uma relação fundamental e primitiva. O nominalismo de semelhança tem variantes: um particular a pode ser $F$ em virtude de se assemelhar a um outro exemplar paradigmático de $F$, ou em virtude de pertencer a uma classe igualitária de particulares

${ }^{6}$ Ver a parte final da Secção 3.

Edição de 2013 
semelhantes.

Russell (1912) é famoso por ter acusado o nominalismo de semelhança de sucumbir a uma forma de regressão viciosa ao infinito:

If we wish to avoid the universals whiteness and triangularity, we shall choose some particular patch of white or some particular triangle, and say that anything is white or a triangle if it has the right sort of resemblance to our chosen particular. But then the resemblance required will have to be a universal. Since there are many white things, the resemblance must hold between many pairs of particular white things; and this is the characteristic of a universal. It will be useless to say that there is a different resemblance for each pair, for then we shall have to say that these resemblances resemble each other, and thus at last we shall be forced to admit resemblance as a universal. The relation of resemblance, therefore, must be a true universal. And having being forced to admit this universal, we find that it is no longer worth while to invent difficult and implausible theories to avoid the admission of such universals as whiteness and triangularity.

A alegada regressão tem a seguinte forma. O facto original a ser explicado é o particular a exemplificar o universal $F$. Esse facto é explicado, num primeiro nível, em termos de semelhança: a é $F$ em virtude de $a$ assemelhar-se a $b$. Introduz-se assim um novo facto: $a$ é semelhante a $b$. Mas esse novo facto também contém um universal: ser semelhante $a$. Se pretendemos explicar esse novo fato eliminando o universal ser semelhante a de forma coerente com o princípio do nominalismo de semelhança, temos de explicá-lo, em termos de semelhança, através de outro facto do mesmo tipo: um facto de semelhança entre, digamos, $c$ e $d$. Mas, nesse novo nível, temos novamente um facto no qual ocorre um universal como constituinte, uma semelhança de segunda ordem, a qual só pode ser eliminada por meio da introdução de uma nova relação de semelhança de ordem superior, e assim por diante ad infinitum.

Existe uma diferença importante entre o argumento de regressão que Russell apresenta contra o nominalismo de semelhança e as regressões apresentadas anteriormente. No caso das regressões no realismo e no nominalismo de classes, o problema consistia basicamente na impossibilidade do proponente da explicação evitar o próprio fenómeno que pretendia explicar, a predicação, o que o levava sempre a um novo nível explanatório. No caso do realismo, o facto predicativo a exemplifica $F$ era explicado em termos da nova predicação a exemplifica a F-idade. No caso do nominalismo de classes, o facto 
predicativo a exemplifica $F$ era explicado em termos da nova predicação a pertence à classe $F$.

O ponto de Russell contra o nominalismo de semelhança é outro: na tentativa de eliminar o universal $F$, que é um constituinte do facto a é $F$, ele introduz um outro universal (não monádico, mas relacional): ser semelhante a. Assim, o projeto nominalista de eliminar universais falha. Segundo Russell, um dos vícios da controvérsia sobre universais consistia na atenção exclusiva dada a propriedades monádicas, esquecendo-se que também relações são universais. Pensou-se assim em eliminar-se o universal $F$, mas não se percebeu que o custo era introduzir outro universal, agora relacional.

É interessante notar que esse problema atinge as outras explicações tradicionais nominalistas: o nominalista de classes introduz o universal ser elemento de, o nominalista de predicados ou de conceitos introduz o universal satisfazer ou cair sob. A única exceção é o nominalista austero, que não propõe explicação alguma. A conclusão parece ser, assim, a de que toda explicação nominalista recorreria, no seu explanans, a algum universal, e que, portanto, o realismo está correto ao afirmar que universais são inevitáveis. Com isso, deslocase a atenção do problema da explicação para o problema da eliminação ontológica.

Existem várias reacções possíveis à regressão ao infinito acima exposta.

Naturalmente, uma possível reacção seria simplesmente aceitar o argumento de Russell como definitivo contra o nominalismo de semelhança. De facto, pelo menos num primeiro momento, Armstrong concordou com Russell que o projecto explicativo do nominalista de semelhança permanece incompleto. Segundo Armstrong (1978: 56), na hierarquia explicativa do nominalismo de semelhança "o nível $n+1$ de semelhança precisa ser postulado a fim de explicar as semelhanças do nível n”.

Outra reação possível seria considerar que as relações de semelhança da hierarquia explicativa são de diferentes ordens e, por isso, a regressão não seria viciosa. Isso foi defendido, por exemplo, por Price (1953) e Küng (1967). No entanto, como Daly (1997) argumenta, a diferença de níveis hierárquicos, por si só, não é suficiente para eximir uma explicação de ser viciosa. Daly também mostra que a sugestão de Campbell (1990), de que a regressão não é viciosa por 
"subir" em direcção a um nível de sempre maior formalidade e menor substancialidade, não colhe. Em toda a regressão ao infinito, "subimos" numa direcção de menor substancialidade e maior formalidade.

Num texto posterior, Armstrong (1989) rejeita a regressão, ao sugerir que cada nível superior de semelhança simplesmente sobrevém em relação ao nível inferior, e, consequentemente, não representa qualquer adição ontológica. De modo semelhante argumentam Campbell (1990) e Simons (1994). De facto, se não considerarmos níveis superiores de explicação como simplesmente sobrevenientes em relação aos níveis inferiores, todas as explicações estariam sujeitas à mesma regressão. Rodriguez-Pereyra (2001) rejeita a solução sugerida por Armstrong porque o preço a pagar seria muito alto para o nominalista de semelhanças. Afinal, segundo este, se $a$ e $b$ são ambos $F$, a semelhança entre $a$ e $b$ sobrevém em relação à sua natureza particular. Mas isso seria justamente abdicar da intuição fundamental do nominalismo de semelhança, a saber, que a natureza dos particulares é determinada pelas suas relações de semelhança, e não vice-versa. Para este nominalismo, $a$ e $b$ têm as suas naturezas em virtude de serem semelhantes. Além disso, Armstrong precisa de supor que se a semelhança sobrevém em relação às naturezas dos particulares, a semelhança não é nada adicional e diferente daquilo relativamente ao qual sobrevém - o que livraria o nominalismo de semelhança de postular a relação de semelhança como elemento adicional e, por consequência, de cair na regressão. Mas, como Rodriguez-Pereyra (2001) argumenta, nem toda superveniência é uma forma de identidade (o próprio Armstrong o reconhece noutros lados, por exemplo em 1997: 56).

Outra possível solução seria considerar a relação de semelhança entre $a$ e $b$ não como um universal, mas como um particular, no mesmo sentido em que um teórico de tropos considera o $F$, em a é $F$, não como um universal, mas como uma propriedade particularizada. Essa sugestão, que é precisamente o alvo da crítica de Russell, é um pouco mais desenvolvida (mas depois rejeitada) por Rodriguez-Pereyra. A solução consistiria em negar que, dados os particulares semelhantes $a, b$ e $c$, o fazedor-de-verdade de 'a é semelhante a b' é $S a b$, que o fazedor-de-verdade de 'b é semelhante a c' é $S b c$, que o fazedor-de-verdade de 'a é semelhante a c' é Sac, que o fazedor-de-verdade de 'a semelhança entre a e b é semelhante à semelhança 
entre b e c' é $S S a b S b c$, etc. Bastaria um enunciado geral da forma: "para todo x e y, se x é semelhante a y, então isso é verdade em virtude de $S_{x y . "}$ O problema dessa solução é que ela não nega, de facto, que existem infinitos fazedores de verdade para uma verdade do tipo 'a é semelhante a b', mas apenas oferece uma maneira universal de dar conta de todos os casos. Além disso, a solução apenas resolve o problema de oferecer fazedores de verdade para todas as verdades. Permanece, no entanto, o problema da hierarquia de fundamento: que $a$ seja semelhante a $b$ em virtude de um facto mais fundamental, o qual seria o caso em virtude de um facto ainda mais fundamental, e assim por diante ao infinito. E, finalmente, essa saída parece fazer o nominalismo de semelhança colapsar com o nominalismo de tropos.

A proposta, aparentemente pouco substancial, de Rodriguez-Pereyra (2001) é a seguinte: $a$ é semelhante a $b$ em virtude de $a$ e $b$ serem o que eles são. Essa solução é formulada em termos de fazedores de verdade: $a$ e $b$ são fazedores de verdade suficientes para a proposição 'a é semelhante a b'. Isso não significa, claro, que 'a existe' e 'b existe' contenham 'a é semelhante a b'. O ponto é que os particulares $a$ e $b$ por si só (sem a sua natureza ou propriedade alguma) são responsáveis pela semelhança. Claro, essa solução só pode colher se adotarmos o realismo modal, segundo o qual cada particular só existe num mundo possível. Assim, para qualquer propriedade $F$, se $a$ é $F$, qualquer particular que não fosse $F$ não seria mais $a$, mas, na melhor das hipóteses, uma contraparte sua. Dessa forma, a mera existência de $a$ e de $b$ garante que ambos sejam $F$. Com isso, o nominalismo de semelhança não precisa de admitir um universal relacional de semelhança, bloqueando a regressão logo no primeiro nível. Uma clara fraqueza dessa opção consiste na sua dependência do realismo modal (o que também vale, claro, para o nominalismo de classes).

Outro ponto considerado fraco em todas as versões do nominalismo de semelhança é o seu carácter contra-intuitivo: dados dois objetos vermelhos, parece plausível supor que ambos são semelhantes porque são vermelhos, e não vice-versa. Dizer que um objeto é vermelho em virtude de ser semelhante a outro objeto torna uma propriedade intrínseca numa propriedade extrínseca do objeto. 


\section{Conclusão}

Concluímos observando que em todas as propostas de explicação da predicação surge a suspeita de haver uma regressão. Mas é preciso distinguir claramente entre dois aspectos: a regressão explicativa e a regressão eliminativa. Do ponto de vista explicativo, não parece haver nenhuma regressão quando se explica a predicação em termos de exemplificação de universais, pertença a uma classe ou semelhança. Note-se que também não há circularidade: a predicação é uma relação entre um particular e um universal, enquanto exemplificação, pertença e semelhança são relações entre particulares. A aparência de uma regressão surge porque a forma linguística de expressar a explicação no primeiro passo sugere uma nova predicação: como apenas se substitui um predicado '... é F' por outro predicado '... exemplifica a F-idade', ‘...pertence à classe F' e '... é semelhante a b' parece que apenas substituímos uma predicação (ou uma propriedade) por outra. Mas, como mostrámos, essas novas relações não são predicações.

Quando se concebe a explicação da predicação como um procedimento que visa a eliminação de universais, como pretende o nominalismo (com excepção do nominalismo austero, de avestruz), a suspeita de uma regressão, de facto, parece mais substancial. O ponto de Russell contra o nominalismo de semelhança consistia nisso: parte-se de um explanandum que contém um universal como constituinte, mas o explanans oferecido contém igualmente um universal. Nos explanans oferecidos tanto pelo nominalismo de classes como no de semelhança temos como constituintes pertencer a e ser semelhante $a$, que são universais, e não particulares (segundo os critérios usuais de reconhecimento de universais: têm ocorrência múltipla, são instanciáveis, são insaturados, e fixam a aridade). Note-se que também o constituinte do explanans realista, exemplificar, é um universal; mas como não se pretende aqui eliminar universais, não há nisso qualquer problema para o realista. Aos nominalistas de classes e semelhança caberia então a tarefa de mostrar como é que, apesar das suas explicações recorrerem a tais entidades, eles não estão comprometidos com elas. 
João Branquinho Universidade de Lisboa

Guido Imaguire Universidade Federal do Rio de Janeiro

\section{Referências}

Armstrong, D.M. 1974. Infinite Regress Arguments and the Problem of Universals. Australasian Journal of Philosophy 52: 191-201.

Armstrong, D. M. 1980. Nominalism and Realism. Volume 1 de Universals and Scientific Realism. Cambridge: Cambridge University Press.

Armstrong, D.M. 1989. Universals: An Opinionated Introduction. Boulder-San Francisco-London: Westview Press.

Armstrong, D.M. 1997. A World of States of Affairs. Cambridge: Cambridge University Press.

Bradley, F.H. 1897. Appearance and Reality. $2^{\text {nd }}$ Edition. Oxford: Oxford University Press.

Campbell, K. 1990. Abstract Particulars. Oxford: Basil Blackwell.

Chisholm, R. 1996. A Realistic Theory of the Categories. Cambridge: Cambridge University Press.

Daly, C. 1997. Tropes. In Properties. Editado por D. H. Mellor e A. Oliver. Oxford: Oxford University Press. pp. 140-159.

Küng, G. 1967. Ontology and the Logistic Analysis of Language. Dordrecht: D. Reidel.

Lewis, D. 1997. New Work for a Theory of Universals. Reimpresso em Properties. Editado por D. H. Mellor e A. Oliver. Oxford: Oxford University Press. pp. $188-227$.

Loux, M.J. 1998. Metaphysics. A Contemporary Introduction. London and New York: Routledge.

Moreland, J.P. 2001. Universals. Chesham: Acumen.

Plato. 1934. Parmenides. Traduzido por A.E. Taylor. Oxford: Oxford University Press.

Price, H.H. 1953. Thinking and Experience. London: Hutchinson's University Library.

Quinton, A. 1973. The Nature of Things. London: Routledge and Kegan Paul.

Rodriguez-Pereyra, G. 2001. Resemblance Nominalism and Russell's Regress. Australasian Journal of Philosophy 70: 395-408.

Rodriguez-Pereyra, G. 2002. Resemblance Nominalism. A Solution to the Problem of Universals. Oxford: Oxford University Press.

Ryle, G. 1939. Plato's Parmenides. Mind 48. Reimpresso em Collected Papers, Vol. I. London: Hutchinson.

Russell, B. 1911. On the Relations of Universals and Particulars. Proceedings of the Aristotelian Society 12. Reimpresso em Logic and Knowledge. Editado por R.C. Marsh. London: Allen and Unwin, 1956.

Russell, B. 1971. The Problems of Philosophy. Oxford: Oxford University Press.

Simons, P. 1994. Particulars in Particular Clothing: Three Trope Theories of Substance. Philosophy and Phenomenological Research 54: 553-75.

Wolterstorff, N. 1970. On Universals. Chicago, Ill: Chicago University Press. 


\section{Apêndice}

\section{A redundância do operador de exemplificação}

1. A exemplificação da Sabedoria $=$ A propriedade de ser um exemplo da Sabedoria (DF)

2. Um objecto x tem a propriedade da exemplificação da Sabedoria se e só se x é um exemplo da Sabedoria (de 1 por Abstracção)

3. A exemplificação da exemplificação da Sabedoria $=$ A propriedade de ser um exemplo da propriedade de ser um exemplo da Sabedoria (DF)

4. Um objecto x tem a propriedade da exemplificação da exemplificação da Sabedoria se e só se x é um exemplo da propriedade de ser um exemplo da Sabedoria (de 3 por Abstracção)

5. A propriedade de ser um exemplo da Sabedoria $=$ A propriedade de ser sábio (DF)

6. x tem a propriedade da exemplificação da exemplificação da Sabedoria se e só se $\mathrm{x}$ é um exemplo da propriedade de ser sábio (de 4, 5 por Substituição)

7. $\mathrm{x}$ tem a propriedade da exemplificação da Sabedoria se e só se x é um exemplo da propriedade de ser sábio (de 2, 5 por Substituição)

8. x tem a propriedade da exemplificação da exemplificação da Sabedoria se e só se $\mathrm{x}$ tem a propriedade da exemplificação da Sabedoria (de 6, 7 por Lógica)

9. A exemplificação da exemplificação da Sabedoria = A exemplificação da Sabedoria (de 8 por Identidade de Propriedades) 